Manuscript accepted for publication in Teaching in Higher Education - accepted 10/05/2017.

\title{
Learning analytics: challenges and limitations
}

Anna Wilson ${ }^{1,2}$, Cate Watson ${ }^{2}$, Terrie Lynn Thompson ${ }^{2}$, Valerie Drew $^{2}$ and Sarah Doyle ${ }^{2}$

${ }^{1}$ School of Social and Health Sciences, Abertay University, Dundee, DDI 1HG, UK

${ }^{2}$ Faculty of Social Sciences, University of Stirling, Stirling, FK9 4LA, UK

a.wilson@abertay.ac.uk 


\section{Learning analytics: challenges and limitations}

Learning analytic implementations are increasingly being included in learning management systems in higher education. We lay out some concerns with the way learning analytics - both data and algorithms - are often presented within an unproblematized Big Data discourse. We describe some potential problems with the often implicit assumptions about learning and learners - and indeed the tendency not to theorize learning explicitly - that underpin such implementations. Finally, we describe an attempt to devise our own analytics, grounded in a sociomaterial conception of learning. We use the data obtained to suggest that the relationships between learning and the digital traces left by participants in online learning are far from trivial, and that any analytics that relies on these as proxies for learning tends towards a behaviourist evaluation of learning processes.

Keywords: learning analytics, Big Data, sociomaterial, professional learning 


\section{Learning analytics: challenges and limitations}

\section{Introduction}

Learning analytics - the collection and (automated) analysis of data concerning learners' backgrounds, behaviours and progress, particularly using data obtained through Learning Management Systems (LMSs) - is increasingly assuming an important role in higher education institutions' planning and accountability processes. As Clow (2013) points out, learning analytics features heavily in documents such as the Horizon Reports (Johnson, Adams and Cummins 2011; Johnson et al. 2012) and in publications aimed at practitioners involved with educational technology, technologyenhanced education, and online and distance learning. Much is claimed with regards to their potential to enhance or even transform learning, suggesting a need to consider them from a critical standpoint. Aside from the ethical issues surrounding the tracking of learners in online spaces, implementations, and learning how to respond to the data generated, may take up significant resources in what is a resource-constrained environment. There thus needs to be demonstrable value in pursuing them institutionwide, in all programmes, courses and modules.

The tendency for learning analytics to be implemented at an institution-wide level stems in part from its technical nature and from a need to justify sufficient investment in their development. As a recent report on the implementation of learning analytics in the Australasian higher education sector notes, 'the complexity of learning analytics initiatives from a technical view has placed it largely in the realm of IT departments or learning analytics specialists' and 'the decision to pursue learning analytics is costly in terms of time, experience and money' (West, Heath and Huijser 2016, np). Similarly, the UK's Higher Education Academy describes learning analytics implementations as '[d]riven by IT departments and library staff alongside enthusiastic 
faculty' (Higher Education Academy, nd). Significant input from typical teaching academics, who may have the best understanding of their own course contexts but for whom the development of reporting functions in LMSs is not a high priority, appears to be rare. The study of the Australian context included a survey of academic staff across the sector; it found that "teaching academics in particular were mostly unaware of the initiatives taking place in their own institutions ... [and] most academics in the survey very rarely had discussions with anyone around learning analytics' (West, Heath and Huijser 2016, np). This is despite the fact that it is these academics who will, ultimately, need to use and interpret such systems.

At the same time, publishers and vendors of LMSs are increasingly providing some form of learning analytics as part of the packages they sell (Williamson 2016a). This may entrench a programmatic, institutional approach, with the same (off-the-shelf) data and algorithms used to monitor learning in all modules, in all disciplines and at all levels. Given the significant ways in which fields vary in their curriculum approaches, it is questionable whether any one generic approach could suit all contexts. One might add to this the question of whether individual learners, who bring a wide variety of prior knowledge and experience to their learning and who may learn and struggle in very different ways (and may be inconsistent in their learning across modules) can be reliably measured with the same behavioural metrics.

This paper lays out some reflections on learning analytics in principle, and then presents digital trace data drawn from a fully-online Masters level module for practising teachers in the primary and secondary sectors in Scotland. Our intention with this analysis is to raise questions about whether using digital traces as proxies for learning can be expected to provide accurate, reliable metrics for student performance on which interventions (especially automated interventions) can be based. 


\section{The rise of learning analytics}

The Society for Learning Analytics Research defines learning analytics as 'the measurement, collection, analysis and reporting of data about learners and their contexts, for purposes of understanding and optimizing learning and the environments in which it occurs' (quoted in Siemens and Gašević 2012, p1). In practice, however, learning analytics is used to label something rather more specific: what Clow (2013) describes as 'the application of ... Big Data techniques' (p684) to data including 'demographic information, online activity, assessment data and final destination data' (p685) to produce metrics which may be presented to student or tutor/instructor in order that they may improve their learning and teaching respectively.

In much of the writing on the topic, there seems to be an implicit assumption that the mass gathering of what amounts to surveillance data is as inevitable in educational contexts as it is in matters of state security. The technical ease and low cost of tracking and storing online activity records, coupled with the normalization of metrics as the primary means of guaranteeing evidence-based practice, are leading to a rather rapid adoption of systems that allow detailed tracking of students' activities in institutional LMSs (Colvin et al. 2016; West, Heath and Huijser 2016), and in the UK to an attempt to establish a national programme of learning analytics (Sclater, Peasgood and Mullan 2016). High hopes for the transformational power of this new evidence base are frequently expressed; for example, Greller and Drachsler (2012) suggest that 'these educational datasets offer unused opportunities for the evaluation of learning theories, learner feedback and support, early warning systems, learning technology, and the development of future learning applications' (p43).

One of the most persuasive arguments for learning analytics is the notion of personalized learning that is expected to 'reduce delivery costs while at the same time 
creating more effective learning experiences, accelerating competence development, and increasing collaboration between learners' (Greller and Drachsler 2012, p42). In particular, personalization is expected to accommodate 'the diversity of learning' (ibid., p53) more effectively than 'current learning environments' (ibid.). Such hopes, however, highlight a potential tension between personalized, individualized learning and the collaborative, socially emergent view of knowledge underpinning both wellestablished learning theories such as social constructivism and its offshoots in communities of practice (Lave and Wenger 1999) or inquiry (Garrison, Anderson and Archer 2001) and in more recent "learning 2.0" theories such as networked learning (Goodyear 2002; Steeples, Jones and Goodyear 2002) and connectivism (Siemens 2005).

\section{Problematizing learning analytics}

Given the widespread uptake of learning analytics (Clow 2013; Siemens and Gašević 2012) and the high hopes expressed above, one key question to ask is how effective learning analytic implementations are at both post-facto analysis and prediction/intervention (another key question - that of the ethics of the enterprise - is beyond the scope of this paper). Here we discuss four potentially problematic aspects: the inconclusiveness of empirical studies; somewhat simplistic conceptions of learning analytics data and methods as part of some generic species, Big Data; choices about data, algorithms and interpretation; and issues around disciplinary and finer-grained differences in pedagogical and learning approaches.

\section{Conflicting findings from empirical studies}

Research in respect of the effectiveness of "inform-and-improve" strategies based on learning analytics seems to be rather ambiguous. 
Some authors report positive findings. For example, one study of students in a fully-online freshman accountancy course (Smith, Lange and Huston 2012) suggests that data such as login frequencies and time on site, supplemented with interim assignment grades, are good predictors of course outcome. Macfadyen and Dawson (2012) report significant correlation between use of discussion forums and LMS-based email, and performance in both fully online and blended learning in a range of modules at a large research-intensive university. Fidalgo-Blanco et al. (2015) use their study of first year biotechnology students enrolled in a course using blended learning approaches to suggest the number of written messages on discussion forums correlates with grades for teamwork. This leads these authors to the somewhat disturbing suggestion that these data could be used to generate such grades automatically.

However, other authors have found apparently contradictory results. For example, Wolff and Zdrahal's (2012) study of historical data concerning over 7500 students in Open University modules suggests that changes in levels of online activity, rather than absolute levels, are the appropriate indicators of the onset of trouble and consequent risks to completion. In contrast to Fidalgo-Blanco et al. (2015), IglesiasPradas, Ruiz-de-Azcárate and Agudo-Peregrina (2014) found no relation between online activity indicators (student-teacher, student-student, student-resource and student-system interactions) and the acquisition of commitment or teamwork in their study of professional teachers undertaking a Masters degree on teaching and new technologies.

The effectiveness of learning analytics in measuring, predicting and improving student performance is thus still open to question. 


\section{Learning analytics and Big Data}

Another aspect of learning analytics that merits explicit problematization is its relation to other activities that are part of what is generally referred to as Big Data. Clow (2013), for example, presents learning analytics data and processing as similar to that in research in the physical sciences, geographical location data processing, and business intelligence systems. However, such discussion perhaps unintentionally implies that Big Data is homogenous and monolithic, spanning data gathered for scientific research, business intelligence and surveillance, when in fact, there is more than one type of Big Data (Lynch 2008); indeed, each of the examples given above uses its own specialist data types.

It also seems to imply that there are automatically applicable 'Big Data techniques' (Clow 2013, p684) that can be used to make sense of any such data. As Clow (2013) suggests, there is a feeling that '[the] volume and scope of data can be so large that it is possible to start with a data-set and apply computational methods to produce results and to seek an interpretation or meaning only subsequently' (p684). Even intentionally critical researchers sometimes slip into a similar discourse, for example describing 'the emergence of big data software and its algorithmic techniques of analysis' (Williamson 2016b, p35). However, not only do the examples of the physical sciences, location data, business intelligence and surveillance all have their own types and formats of data; they also have their own specialist methods for organizing and interpreting these.

In a separate piece (Wilson et al. 2017a), we compare learning analytics data and data processing with three other examples that fall under the banner of Big Data in an attempt to draw out the ways in which data and analytics in an educational context might differ from or be similar to data and analytics in other fields. In particular, we 
emphasize that Big Data in the physical sciences refers to data obtained in highly controlled, carefully designed, replicable experiments, while learning analytics data is collected incidentally and in circumstances that differ for every single user-resource or user-user interaction. The data analytics of the physical sciences are reconstructive, using rules provided by underpinning theories and aiming to distinguish certain rare events from a much larger background of common occurrences, while learning analytics aim to be predictive and prescriptive, with the explicit intention of feeding back into and changing the system they measure.

The actual collection, treatments and uses of learning analytic data in practice have more in common with business intelligence analytics. Targeted advertising is translated into personalized learning (Williamson 2016b); it is assumed that, just as customers can be guided towards better shopping habits, students can be guided towards better learning habits. "Recommender systems" can tell learners what to read, who to talk to, or what to do next: 'Just as Amazon.com uses the data from our purchase history to make suggestions about future purchases, so can learning analytics allow us to suggest new learning opportunities or different courses of action to our students' (DietzUhler and Hurn 2013). However, one might question how effective these personalization systems are: studies in the business context have proved ambiguous (compare, for example, Pathak et al. 2010 and Lee and Hosanagar 2014), highlighting the fact that the computational techniques involved are complex, varied and not always well-proven.

Concerns have also been raised about the cultural impact of automated personalization in the online business context - concerns that may be equally applicable in the learning context. On the one hand, it has been suggested that recommender systems may result in increased insularity and fragmentation, leading users to more of 
what they already know or are familiar with rather than exposing them to new ideas and cultures beyond their existing interests and biases (Sunstein 2007). On the other hand, there is empirical evidence to suggest that personalization results in increased homogenization (Hosanagar et al. 2013) - but by guiding a large number of people to a limited number of popular resources, rather than by increasing the range of resources and ideas that all users are exposed to (Lee and Hosanagar 2014). Similar concerns have been expressed regarding learning analytics (Williamson 2016b;2016c), with even proponents of learning analytics such as Greller and Drachsler noting that 'aligning and regulating performance and behaviour of individual teachers or learners against a statistical norm without investigating the reasons for their divergence may strongly stifle innovation, individuality, creativity and experimentation' (Greller and Drachsler $\mathrm{p} 47)$.

The equivalence of business intelligence analytics and learning analytics is, thus, open to question.

\section{Problematizing data and analytical algorithms}

These concerns regarding the effectiveness of learning analytics and their relation to business intelligence point to a more basic question as to what, exactly, is being analysed and how it relates to learning.

Reflecting on the increasing separation of data science and critical educational research approaches, Williamson (2016a) poses the question, 'What methodologies might be required of critical education researchers to examine the emerging digital methods of algorithmists and education data scientists as they stake their claim to expertise in educational research and knowledge production?' (p5). Questions as to what is being measured, why it might be useful, how it relates to learning, the ethics of 
blanket surveillance, and even the ethics and desirability of personalizing learning or requiring social interaction merit serious critical consideration and debate.

Such questions relate to the sociotechnical entanglement of algorithms, code, and the interests and activities of learners, educational institutions and commercial orgnaizations. As well as the on-going challenge to formulate indicators from the available datasets that bear relevance for the evaluation of the learning process' (Greller and Drachsler 2012, p49), we need to bear in mind that assumptions about humans and society are implicitly coded into algorithms. There is thus a risk that learning analytic systems may reproduce and entrench existing biases such as class, gender, ethnicity. Learning analytics and their representations require new levels of data literacy and competences in interpretation from their users that may be difficult to develop. There is also a danger that sophisticated data visualizations may serve to misdirect attention (Greller and Drachsler 2012; Williamson 2016b; 2016c). A critical sensitivity to such issues is essential to planning, implementing and interpreting the results of learning analytics.

\section{Allowing for pedagogical variation}

The variations and apparent contradictions in the research findings discussed above may be the result of differences in data collection, processing algorithms and interpretation; but they may also be due to issues such as the fundamental differences in the kinds of learning going on in different courses and at different levels. Some authors have already described the need to take contextual factors such as student and staff demographics, institutional culture and vision, and the size and budget of the institution into account when implementing learning analytics (Gašević et al. 2015; West, Heath and Huijser 2016), but differences may occur at an even more granular level, such as 
discipline and level. For example, it has been suggested that disciplines and fields are characterized by signature pedagogies (Shulman 2005) and disciplinary threshold concepts (Meyer and Land 2013). Certainly, different disciplines require and deploy different learning activities for students, and assess performance and learning outcomes using different modes. It would thus make sense to expect different characteristic markers for learning in terms of online, digital traces. Such considerations suggest that any analytics must be carefully designed and tailored for context, rather than applied in generic, pan-institutional fashion.

\section{Theorizing learning analytics}

The concerns raised above suggest a need for a more explicit theorization of learning analytics: as Knight et al. (2014) put it, 'we must understand the underlying structure of the phenomenon we seek to explore with analytics prior to digging into the data' (p1681). Learning analytics are only likely to effectively and reliably enhance learning outcomes if they are designed to measure and track signals that are genuine indicators of or proxies for learning. To do this, they need to be grounded in robust and clearly articulated theories of learning.

In much of the literature, learning is described as "taking place online" and data such as click records and page hits as "learning data" (see, e.g., Clow 2013; Greller and Drachsler 2012) rather than questionable proxies for learning. The belief that the statistical analyses at the heart of learning analytics can succeed at all seems to rest on one of, or a combination of, two sets of hypotheses: either:

- There are such things as generically or group-specifically desirable learning behaviours;

- We know or can tell from click data and so on what those behaviours are; and 
- They can be (reasonably accurately) measured by the data available to analytical implements attached to or embedded in LMSs.

or:

- Individual students have repeated and consistent approaches to and experiences of learning (their "learning style");

- Sufficient data are available and well-enough understood to diagnose each student's unique learning style; and

- Tailored suggestions for learning that suit both style and context can be algorithmically generated from these data.

These assumptions imply that, for learning analytics to achieve the transformational power that is hoped for it, these signature behavioural patterns must be identified.

Proponents of large-scale, institutional uptake of learning analytics packages based on business intelligence approaches might argue that studies of learning analyticsinformed interventions have shown improved student outcomes and that this implies that a behaviourist assessment of the activities of online leaners is both valid and sufficient. Purdue's Course Signals, for example, has been shown to improve student retention by alerting students who were relatively inactive on their course sites compared to their peers (Arnold and Pistilli 2012). We do not wish to argue that gathering and processing user data in such a way is not potentially useful - while it might be argued that "good" online tutors are aware of and follow up on not only inactivity but also quality of online contributions, some automation and early warning may indeed be an advantage when class numbers are large and tutor:participant ratios small. However this might be more helpfully described as activity analytics, rather than learning analytics. As Gourlay (2017) has pointed out, there is a danger in equating 
activity, engagement and learning. The very fact that increased attention or participation can lead to improved performance suggests that the problems, if any, experienced by the students at risk in these situations had little to do with learning per se, and perhaps originated in factors such as competing commitments, time management, or feelings of alienation. If a warning that you are not spending enough time online is sufficient to improve your commitment and performance, you are probably not experiencing significant conceptual difficulties with the material. The fact that some interventions have been shown to result in larger improvements in performance among those students already doing well as compared to those who are struggling may lend further support to this argument.

Recent efforts to ground learning analytics in learning theories have tended to draw upon networked learning (Goodyear 2002; Steeples, Jones and Goodyear 2002) or connectivist theories (Siemens 2005). These theories essentially posit that students who are more connected to a (social) network of other learners are more likely to succeed. This has led to recent developments incorporating the tools of Social Network Analysis (Scott 2012) into learning analytic systems (Badge, Saunders and Cann 2011; de Laat et al. 2007; Hecking, Ziebarth and Hoppe 2014; Schreurs et al. 2013; Wise, Zhao and Hausknecht 2013).

The least sophisticated analytics informed by these theoretical perspectives essentially count the number of times students participate in discussion forums. Such implementations identify those students that contribute less than the average and let them know that this is the case through dashboard displays, or flag up low participation to instructors so that they may contact the student themselves. More sophisticated versions of this approach include counting "listening" interactions as well as "talking" in forums (Wise, Zhao and Hausnecht 2013). Other analytics informed by networked 
learning perspectives employ or envisage employing natural language processing software to analyse the development of ideas in a series of written assignments (Lárusson and White 2012) or the quality of contributions to forums (Ferguson and Buckingham Shum 2011). This latter example speculates that if software can identify posts to forums that can be characterized as exploratory talk, automated feedback could be generated letting students know that they are not talking in the desired way, and prompting them with examples of how to do so.

However, as noted above, the empirical evidence that higher levels of contribution to online discussions correlate with higher levels of achievement is ambiguous. Even more significantly, there is little or no evidence that encouraging more contributions from those who are struggling (or not contributing for some other reason) increases their levels of achievement. That is, while a behavioural pattern may be identified among the majority of those students who do well or poorly on assessment tasks, there is not a substantial understanding of whether this is a symptom or a cause. Arguments might be made drawing on Vygotsky's zone of proximal development, and/or Garrison's model of online communities of inquiry (Garrison, Anderson and Archer 2001), but they remain undemonstrated empirically.

\section{Sociomateriality: an alternative theoretical perspective}

Purely social models of learning rather neglect an important part of students' experiences: the material or non-human. This may be particularly important in online environments. Here, a sociomaterial perspective (Fenwick, Edwards and Sawchuk 2015), which recognizes the role of the material, would encourage us to take into account the hardware and software - the devices used by students and the platforms through which courses and modules are "delivered". Such concerns are (or should be) 
an important influence on module and interface design, and on the design of dashboards and other features that are meant to provide feedback from learning analytics software. However, they should also influence both our conceptions of the interactions being recorded in the digital environment, and the design of any analytics used to monitor and process them. One might imagine, for example, approaches to evaluating learning and progress that are based on the concepts of actor-network theory (Latour 2005), perhaps seeking to identify obligatory passage points or (im)mutable mobiles. Alternatively, one might adopt a perspective drawn from complexity theory (Byrne 1998), and try to look for emergent patterns as networks or assemblages of learners and learning materials are formed. Here, we start the process of imagining how digital trace data analytics might be influenced and shaped by such perspectives.

First, when considering online interactions, a sociomaterial perspective might remind us that students are never wholly "in" the online environment. They remain, substantially, in their home or library, on public transport, etc. Only part of them is distributed or extended into the LMS, and only sporadically at that. We do not observe learning online; we do not even observe students online. We observe indications of electronic or optical interactions that create ephemeral assemblages of student/device/network/LMS-server/digital-resource. The digital resource may be an authoritative piece authored by an instructor; a post left by another student; a reflection in the student's own blog, and so on. These in turn may be viewed as the residues of other ephemeral or transient assemblages, of instructor/device/network/LMS-server, or peer/device/network/LMS-server, for example. How these records or residues of such transient assemblages relate to learning requires exploration and theorization before they can be "mined" as "learning data". 


\section{A case study}

Motivated by a desire to explore the relationships between digital records and residues inevitably the data on which automated analytics feed - and learning, we created a series of analytics based around data easily obtainable by instructors from our Blackboard-based LMS. We studied data from a Master's level module intended to be the first module in a professional learning programme for practising teachers. The key aim of this module was to use collaborative professional learning to develop participants' critical engagement with educational policy (Watson et al. 2016); the intention was to exploit the multiplicity of perspectives arising from disciplinary affiliation, level, geographic location, social conditions and other past experiences of the participants. It thus provides a good example of a module in which both online and social forms of learning are deemed essential, rather than merely helpful or incidental, and which explicitly aims for the complex, higher order learning that is often thought of as characteristic of higher education (Davies and Barnett 2015).

Because the students in the module are themselves teachers, and because the role of those delivering the module was facilitation and feedback rather than content delivery, we henceforth refer to the former as participants and the latter as tutors. Following an initial face-to-face orientation day, the module was delivered in wholly online format. It was designed from the first to be on online course, and thus was not structured around lectures (recorded or otherwise) but instead around readings and participatory online activities. It consisted of five stepped phases: first, an induction period led participants to undertake a range of activities aimed at familiarizing them with the LMS site and introducing them to tools such as discussion forums, blogs and wikis. Next, participants were introduced to critical frameworks that they might use in their subsequent study, and to the notion of professional literacies. During this stage, 
participants were required to contribute to a series of discussion forum topics. In the next phase, participants read and blogged about notions of professionalism and professional practice. Participants were then assigned to groups and asked to create a wiki presenting a critical analysis of an educational policy issue of their choice. In the final phase, participants were asked to produce a short but more formal, academic piece of writing critiquing an issue of their choice, and to reflect on their own learning during the module; these two tasks formed the basis for assessment. All participant writing in the module was essentially public within the module site (with the exception of the final assessed pieces), and participants were encouraged (and at some points required) to reply to and comment on the points made by their peers in the forums, blogs and wikis; for these purposes, they were organized into two groups, each facilitated by their own tutor.

Following approval from our institution's Human Ethics Committee, we sought and obtained informed consent from participants in the module allowing both their online activities and written work to be used in research. The data we used to develop and explore our own learning analytics were drawn from all of the 43 participants in the module. Of these, four did not complete the module and five were required to re-write their final pieces of assessed writing in order to pass the course. These participants thus form a group that learning analytics might aim to identify as at risk, and so provide feedback and guidance to improve their learning outcomes. Eight participants were identified as having performed particularly well, on the basis of the qualitative feedback provided to them at the end of the module by the module tutors. This group might then provide an indication of the type or types of behaviour that a learning analytics system would use as a template to compare other participants to. We drew on tools developed for Social Network Analysis to visualize and analyse the traces and residues themselves. 
Participant activity reports generated through the LMS do not contain information on all types of online interaction. Tracking information was available on participant interactions with instructor-created resources; on discussion forum contributions; and on times spent both on site and on particular pages. Tracking data on contributions to wikis and blogs, however, was not provided in the reporting functions.

Our approaches to analysing the available data included the visualization of patterns of ephemeral assemblage formation between participants and instructor-created resources, as individuals logged onto the system and accessed different pages and files. We also developed visualization and analytic techniques around the residues of multiple, sequential, ephemeral assemblage formation left in records of discussions forums (Wilson et al. 2017b). The present paper focuses on the former, and what they suggest about the limits of what digital traces may tell us about learning.

\section{Patterns of ephemeral assemblage formation between participants and instructor-created resources}

Figure 1 shows patterns of participant/instructor-created-resource interaction in the first four blocks of time/activity in the module.

In each panel, the traces of participants are represented by black circles, while the digital resources they interact with are represented by coloured squares; the ephemeral assemblage formed when the participant connected to a particular resource is then represented by the arrows drawn between them. The colours indicate resources associated with different topics or types; for example, red squares represent resources relating to the induction phase; blue squares represent resources describing criticality frameworks; green squares represent resources describing professional literacies and notions of professionalism; yellow squares represent module introduction and overview 
documents; and gold squares represent documents providing advice on how to study or interact in an online community.

\section{FIGURE 1 ABOUT HERE}

As observed by Hecking, Ziebarth and Hoppe (2014) in their study of resourcebased learning in an online module, it appears that participant/resource interactions cluster into different patterns. Note the algorithm used to lay the networks out (Clauset, Newman and Moore 2004) is deliberately designed to emphasize similarity and difference; the separate clusters of participants in each panel of the figure do not use exclusively different resources. Some resources were accessed by all groups, which leads to cross-group connections.

The top left panel represents the induction period. During this time, participants' behaviours fell into four broad groups: all connected with the intended induction materials, but the groups differed in what other materials they connected to. Group A1 focused on the induction materials, connecting to little else. Group A2 connected to documents providing advice on online learning. Group A3 connected to many of the module's overview and introductory (learning pathway) resources. Group A4 differentiated themselves by connecting to resources explicitly addressing the next two activities.

The top right panel represents a period during which participants were expected to read some instructor-provided resources introducing two frameworks for critical thinking and critical reading while the bottom left panel represents the subsequent period where the reading materials introduced the notion of professional literacies. Both periods were capped by participation in related, week-long discussion forums. During the former period, all participants connected to both criticality-related resources 
and those relating to the upcoming professional literacies topic; however, two groups differentiated themselves by either continuing to connect to the induction materials plus advice about learning online (Group B2) or by reading ahead and connecting to materials related to future tasks and topics (Group B3). During the subsequent "professional literacies" period, all participants connected to the relevant resources, however some continued to access the induction resources (Group C1) and the criticality-related resources (Group C2). A third group (Group C3) connected to learning pathway resources and advice about online learning. Group C4 looked ahead, connecting to resources related to future activities.

The bottom right panel represents the next phase of the module, devoted to professionalism and professional practice. Again, all participants connected to at least some of the relevant resources, but two groups emerged that either also connected to learning pathway resources and advice on online learning (Group D2) or read ahead, connecting to resources related to the next part of the module (Group D3).

There are thus, during each of these four periods, groups of participants who (i) focus solely on the materials needed for the task at hand; (ii) connect to the appropriate resources but also frequently refer to the learning pathway documentation and advice on online learning; and (iii) regularly look ahead to the resources related to the next stage of the module. There are also participants who refer back to resources related to earlier stages. While there is some movement of participants between these groups - and in particular there was no stable group of participants accessing resources from earlier stages - there are some participants who regularly exhibit the same patterns of behaviour, either always focussing on the currently-required resources, always accessing the learning pathway and advice resources, or always looking ahead. 
There are thus relatively clearly separable patterns among the module participants differentiating how they connect to instructor-created materials. These are perhaps the kind of emergent patterns of interaction that a complex systems approach would try to detect. One might speculate as to the reasons underlying these different behaviours, raising questions that would be interesting to address in future research. Perhaps those who frequently connect to the learning pathway and advice documents do so because they are feeling uncertain or even lost? Perhaps those accessing resources from past stages are a little behind, or uncertain and need to remind themselves of what they should by then already have mastered? Or perhaps when they first clicked on them, they did not really read them deeply, or only had time to read strategically, and are now choosing to return to enrich their learning? Perhaps those looking ahead are confident and eager to move on, or are more organized than others, carefully planning their learning? Or perhaps they are feeling uncertain about where their current activities are leading them?

These are the kind of distinctive patterns, going beyond mere frequency of access, that learning analytics algorithms might be programmed to identify. However, the utility of such a system depends on there being a correlation between different patterns and different learning outcomes. If we look at the group of participants who participated throughout the module but failed to complete and those who were required to resubmit their final assignment, we find that they are generally distributed across the groups, sometimes reading ahead, sometimes referring back, sometimes accessing the pathway and advice materials, sometimes focussing on the task at hand. Of the participants who performed particularly well, some consistently accessed the pathway and advice materials and some consistently accessed materials related to future stages of the module, but others moved between these groups and occasionally could be found 
focussing on the task at hand or referring back to previous resources. There is some correlation between accessing overview documents and good performance, and one might argue that the habit of regularly orienting oneself by referring to overview documents and guidance on how to learn online is likely to support learning. However, an automated recommender system that suggested looking at overview documents to participants who were not doing so does not seem likely to overcome any conceptual or workload problems that those participants might be struggling with, if indeed they are struggling at all, since some of the best-performing participants did not exhibit this habit. Equally, looking ahead is more likely to be a symptom of successful learning than its cause, and one can image the ways in which a recommender system that suggested such behaviour to participants might backfire.

The data suggest that analysis at the crude level of the total number of participant connections with resources on the site may not be completely reliable either. The two sequences of images in Figure 2 below compare the traces of the assemblages with resources formed by two different participants (upper and lower panels) in the three periods above following the induction week.

The participant whose traces are displayed in the upper panels forms assemblages with almost no instructor-created resources in the online space, often not even connecting to the nominally required resources. (Of course, we have no idea what she is up to in the offline world.) She also contributed lower than average to discussion forums throughout the module. This is the kind of pattern that would result in warnings from typical learning analytics systems, and yet this participant was among those whose final piece of work was assessed as high quality by the module tutors.

FIGURE 2 ABOUT HERE 
In contrast, the participant whose traces are displayed in the lower panels connects to all the required resources, looks ahead to forthcoming topics and activities, and makes a slightly above average contribution to the discussion forums. It would be difficult to design learning analytics that would trigger a warning based on this kind of average to apparently good behaviour (without creating a system that generated warnings for almost all participants, all of the time). And yet this participant was one of the group who were required to resubmit the formal assessment item, and thus might be judged as having poorer learning outcomes.

These two participants may be examples of the outliers that Greller and Drachsler (2012) admit statistically-based learning analytics will never be able to predict - but they provide a powerful illustration of the uniqueness of each learner.

\section{Implications and conclusion}

This examination of learning analytics highlights the limits of relying on automated analytics based on pattern-identification processes.

In the last section of this paper, we have provided an example of how learning analytics might be attempted from a particular theoretical perspective: in this case, a sociomaterial theory of learning which led us to view the online module as comprising a series of ephemeral assemblages of digital objects and users of the LMS. We used the digital data available to us to look for correlations between different online interactions with instructor-created resources. We have demonstrated that discernible differences in patterns of interaction between students and resources are, indeed, present; and it appears that these differences are marked enough that they could be identified in automated, machine-based processes. However, despite our own subscription to 
sociomaterial theories of learning, we also found that we have been pushed towards a behaviourist approach by the reliance of this type of data analysis on digital traces as proxies for learning.

In fact, we have shown that the relationships between patterns of interaction in the online space are not simply and rigidly correlated with final performance. Although it is possible that performance on the final, assessed tasks of this module does not itself correlate with actual learning outcomes or benefits accrued to the participants in terms of increased knowledge, skills or confidence, it certainly correlates with formal learning outcomes which govern whether the participant is able to progress to subsequent modules in the programme. It is thus an important thing for analytical systems to be able to account for and, in principle, predict.

If learning analytics such as these were to be used to generate warnings and recommendations for action on the basis of comparison with average interaction rates and patterns, some of the module participants who in the end performed very well would have been bombarded with warnings and recommendations to do more, interact with more, click on more, and download more - that is, to perform as more active participants in the online space. Whether this would have been beneficial to those participants is questionable.

Similarly, the same kind of analytics would not pick up on a group of participants who appeared to be active, interacting with appropriate materials and resources at appropriate times, but who in the end did not adequately demonstrate the desired learning outcomes in the final assessed tasks. An alternative approach might be to take the patterns exhibited by participants who performed well in this round of the module and use them as templates with which to compare participant performance in future rounds of the module - however, the interaction patterns of this group of 
participants was quite varied. Indeed, as may be evident from the example shown in Figure 2, some of the participants in this group interacted very little online - and it is hard to envisage a warning system that tells participants they are at risk of doing too much, or a recommender system that encourages participants to interact less.

If anything, the participant/resource interaction data generated from this module are a powerful illustration of just how diverse approaches to study and online spaces are. They suggest that it may be more important to recognize, accommodate and even celebrate that diversity, rather than discourage it by pushing people to some behavioural norm that most likely corresponds to an average of all outcomes, rather than the best outcome for each participant.

This example of what a detailed analysis of learning analytic data might look like reinforces the concerns raised in the first half of this paper regarding a rush to embrace and implement learning analytic programmes. The argument and examples we have presented undermine some of the more general claims that have been made for learning analytics, and so demonstrate why it is important to remain sceptical about such claims. In particular, they provide a clear illustration of why it is important to bear in mind the difference between learning and activity - a distinction that is too often forgotten in discussions of active learning (Gourlay 2017). We hope that this paper prompts further debate, reflection and exploration (for example of disciplinary or pedagogy-related differences), allowing for more critical engagement with and critique of such programmes.

\section{References}

Arnold, K. E., and Pistilli, M. D. (2012). Course signals at Purdue: using learning analytics to increase student success. In Proceedings of the 2 nd International 
Conference on Learning Analytics and Knowledge (LAK'12), 29 April - 02 May, Vancouver, Canada, pp. 267-270.

Badge, J. L., Saunders, N. F., and Cann, A. J. (2012). Beyond marks: new tools to visualise student engagement via social networks. Research in Learning Technology, 20.

Byrne, D. S. (1998). Complexity theory and the social sciences: an introduction. London: Routledge.

Clow, D. (2013). An overview of learning analytics. Teaching in Higher Education, 18(6), 683-695.

Davies, M. and Barnett, R. (2015). The Palgrave Handbook of Critical Thinking in Higher Education. New York: Palgrave Macmillan.

Clauset, A., Newman, M. E., and Moore, C. (2004). Finding community structure in very large networks. Physical Review E, 70(6), 066111.

Colvin, C., Rogers, T., Wade, A., Dawson, S., Gašević, D., Buckingham Shum, S., Nelson, K., Alexander, S., Lockyer, L., Kennedy, G., Corrin, L., and Fisher, J. (2016). Student retention and learning analytics: a snapshot of Australian practices and a framework for advancement. Canberra, ACT: Australian Office for Learning and Teaching. Available online at http://www.olt.gov.au/project$\underline{\text { student-retention-and-learning-analytics-snapshot-currentaustralian-practices- }}$ and-framework. Accessed 08/02/2017.

De Laat, M., Lally, V., Lipponen, L., and Simons, R. J. (2007). Investigating patterns of interaction in networked learning and computer-supported collaborative learning: A role for Social Network Analysis. International Journal of Computer-Supported Collaborative Learning, 2(1), 87-103.

Dietz-Uhler, B., and Hurn, J. E. (2013). Using learning analytics to predict (and improve) student success: A faculty perspective. Journal of Interactive Online Learning, 12(1), 17-26.

Fenwick, T., Edwards, R., and Sawchuk, P. (2015). Emerging approaches to educational research: Tracing the socio-material. London: Routledge.

Ferguson, R., and Shum, S. B. (2011). Learning analytics to identify exploratory dialogue within synchronous text chat. In Proceedings of the 1st International Conference on Learning Analytics and Knowledge (LAK'11), 27 Feb - 01 Mar 2011, Banff, Canada, pp. 99-103. 
Fidalgo-Blanco, Á., Sein-Echaluce, M. L., García-Peñalvo, F. J., and Conde, M. Á. (2015). Using Learning Analytics to improve teamwork assessment. Computers in Human Behavior, 47, 149-156.

Higher Education Academy. (nd). Learning Analytics. HEA Starter Tools. Available online at https://www.heacademy.ac.uk/enhancement/starter-tools/learninganalytics. Accessed 08/02/2017.

Garrison, D. R., Anderson, T., and Archer, W. (2001). Critical thinking, cognitive presence, and computer conferencing in distance education. American Journal of Distance Education, 15(1), 7-23.

Gašević, D., Dawson, S., Rogers, T., and Gasevic, D. (2016). Learning analytics should not promote one size fits all: The effects of instructional conditions in predicting academic success. The Internet and Higher Education, 28, 68-84.

Goodyear, P. (2002). Psychological foundations for networked learning. In Networked learning: Perspectives and issues (pp. 49-75). London: Springer.

Gourlay, L. (2017). Student Engagement, 'Learnification' and the Sociomaterial: Critical Perspectives on Higher Education Policy. Higher Education Policy, 30(1), 23-34.

Greller, W., and Drachsler, H. (2012). Translating learning into numbers: A generic framework for learning analytics. Journal of Educational Technology and Society, 15(3), 42-57.

Hecking, T., Ziebarth, S., and Hoppe, H. U. (2014). Analysis of Dynamic Resource Access Patterns in Online Courses. Journal of Learning Analytics, 1(3), 34-60.

Hosanagar, K., Fleder, D., Lee, D., and Buja, A. (2013). Will the global village fracture into tribes? Recommender systems and their effects on consumer fragmentation. Management Science, 60(4), 805-823.

Iglesias-Pradas, S., Ruiz-de-Azcárate, C., and Agudo-Peregrina, Á. F. (2015). Assessing the suitability of student interactions from Moodle data logs as predictors of cross-curricular competencies. Computers in Human Behavior, 47, 81-89.

Johnson, L., Adams, S., and Cummins, M. (2012). The NMC Horizon Report: 2012 Higher Education Edition. Austin, TX: The New Media Consortium. http://www.nmc.org/pdf/2012-horizon-report-HE.pdf. 
Johnson, L., Smith, R., Willis, H., Levine, A. and Haywood, K. (2011). The 2011 Horizon Report. Austin, TX: The New Media Consortium. http://net.educause.edu/ir/library/pdf/hr2011.pdf.

Knight, S., Wise, A. F., Arastoopour, G., Williamson Shaffer, D., Buckingham Shum, S., and Kirschner, P. A. (2014). Analytics for learning and becoming in practice. In International Conference of the Learning Sciences (ICLS 2014), 23-27 June 2014, Boulder, Colorado, pp. 1680-1683.

Lárusson, J. A., and White, B. (2012). Monitoring student progress through their written point of originality. In Proceedings of the 2nd International Conference on Learning Analytics and Knowledge (LAK'12), 29 April - 02 May, Vancouver, Canada, pp. 212-221.

Latour, B. (2005). Reassembling the social: An introduction to actor-network-theory. Oxford: Oxford University Press.

Lave, J., and Wenger, E. (1999). Learning and pedagogy in communities of practice. In Learners and pedagogy, ed.s Leach, J. and Moon, B., p 21-33. London: Sage.

Lee, D., and Hosanagar, K. (2014). Impact of Recommender Systems on Sales Volume and Diversity. In Proceedings of the International Conference on Information Systems (ICIS 2014), 14-17 December 2014, Auckland, New Zealand, n.p.

Lynch, C. (2008). Big data: How do your data grow? Nature, 455(7209), 28-29.

Macfadyen, L. P., and Dawson, S. (2012). Numbers are not enough. Why e-learning analytics failed to inform an institutional strategic plan. Journal of Educational Technology and Society, 15(3), 149-163.

Manouselis, N., Drachsler, H., Vuorikari, R., Hummel, H., and Koper, R. (2011). Recommender systems in technology enhanced learning. Recommender Systems Handbook, ed.s Ricci, F., Rokach, L., Shapira, B. and Kantor, P. B. (pp. 387 415). New York: Springer.

Meyer, J., and Land, R. (2013). Overcoming barriers to student understanding: Threshold concepts and troublesome knowledge. London: Routledge.

Pathak, B., Garfinkel, R., Gopal, R. D., Venkatesan, R., and Yin, F. (2010). Empirical analysis of the impact of recommender systems on sales. Journal of Management Information Systems, 27(2), 159-188.

Ramsden, P. (2003). Learning to teach in higher education. London: Routledge. 
Ricci, F., Rokach, L., and Shapira, B. (2011). Recommender Systems Handbook. New York: Springer.

Schreurs, B., Teplovs, C., Ferguson, R., De Laat, M., and Buckingham Shum, S. (2013). Visualizing social learning ties by type and topic: Rationale and concept demonstrator. In Proceedings of the Third International Conference on Learning Analytics and Knowledge, 08-12 April 2013, Leuven, Belgium, pp. 33-37.

Sclater, N., Peasgood, A. and Mullan, J. (2016). Learning Analytics in Higher Education. London: Jisc. Available online at https://www.jisc.ac.uk/sites/default/files/learning-analytics-in-he-v3.pdf. Accessed 08/02/2017.

Scott, J. (2012). Social network analysis. London: Sage.

Shulman, L. S. (2005). Signature pedagogies in the professions. Daedalus, 134(3), 5259.

Siemens, G. (2005). Connectivism: A learning theory for the digital age. Journal of Instructional Technology and Distance Learning 2(1), n.p.

Siemens, G., and Gašević, D. (2012). Guest editorial-learning and knowledge analytics. Journal of Educational Technology and Society, 15(3), 1-2.

Smith, V. C., Lange, A., and Huston, D. R. (2012). Predictive Modeling to Forecast Student Outcomes and Drive Effective Interventions in Online Community College Courses. Journal of Asynchronous Learning Networks, 16(3), 51-61.

Steeples, C., Jones, C., and Goodyear, P. (2002). Beyond e-learning: A future for networked learning (pp. 323-341). London: Springer.

Sunstein, C.R. (2007). Republic.com 2.0. Princeton: Princeton University Press.

Watson, C., Wilson, A. N., Drew, V. M., and Thompson, T. L. (2016). Criticality and the exercise of politeness in online spaces for professional learning. The Internet in Higher Education, 31, 43-51.

West, D., Heath, D. and Huijser, H. (2016). Let's Talk Learning Analytics: A Framework for Implementation in Relation to Student Retention. Online Learning 20(2), np.

Williamson, B. (2016). Digital education governance: An introduction. European Educational Research Journal, 15(1), 3-13. 
Williamson, B. (2016). Digital methodologies of education governance: Pearson plc and the remediation of methods. European Educational Research Journal, 15(1), 3453.

Williamson, B. (2016). Digital education governance: data visualization, predictive analytics, and 'real-time' policy instruments. Journal of Education Policy 31(2), 123-141.

Wilson, A. N., Thompson, T. L., Watson, C., Drew, V. M. and Doyle, S. (2017). Big Data: plural/singular. First Monday, 22(4), np.

Wilson, A. N., Watson, C., Drew, V. M., Thompson, T. L. and Doyle, S. (2017). Tracing conversations in discussions. In preparation.

Wise, A. F., Zhao, Y., and Hausknecht, S. N. (2013). Learning analytics for online discussions: a pedagogical model for intervention with embedded and extracted analytics. In Proceedings of the Third International Conference on Learning Analytics and Knowledge, 08-12 April 2013, Leuven, Belgium, pp. 48-56.

Wolff, A., and Zdrahal, Z. (2012). Improving retention by identifying and supporting “at-risk" students. Educause Review Online. Wednesday $18^{\text {th }}$ July 2012. Available online at http://er.educause.edu/articles/2012/7/improving-retentionby-identifying-and-supporting-atrisk-students. 


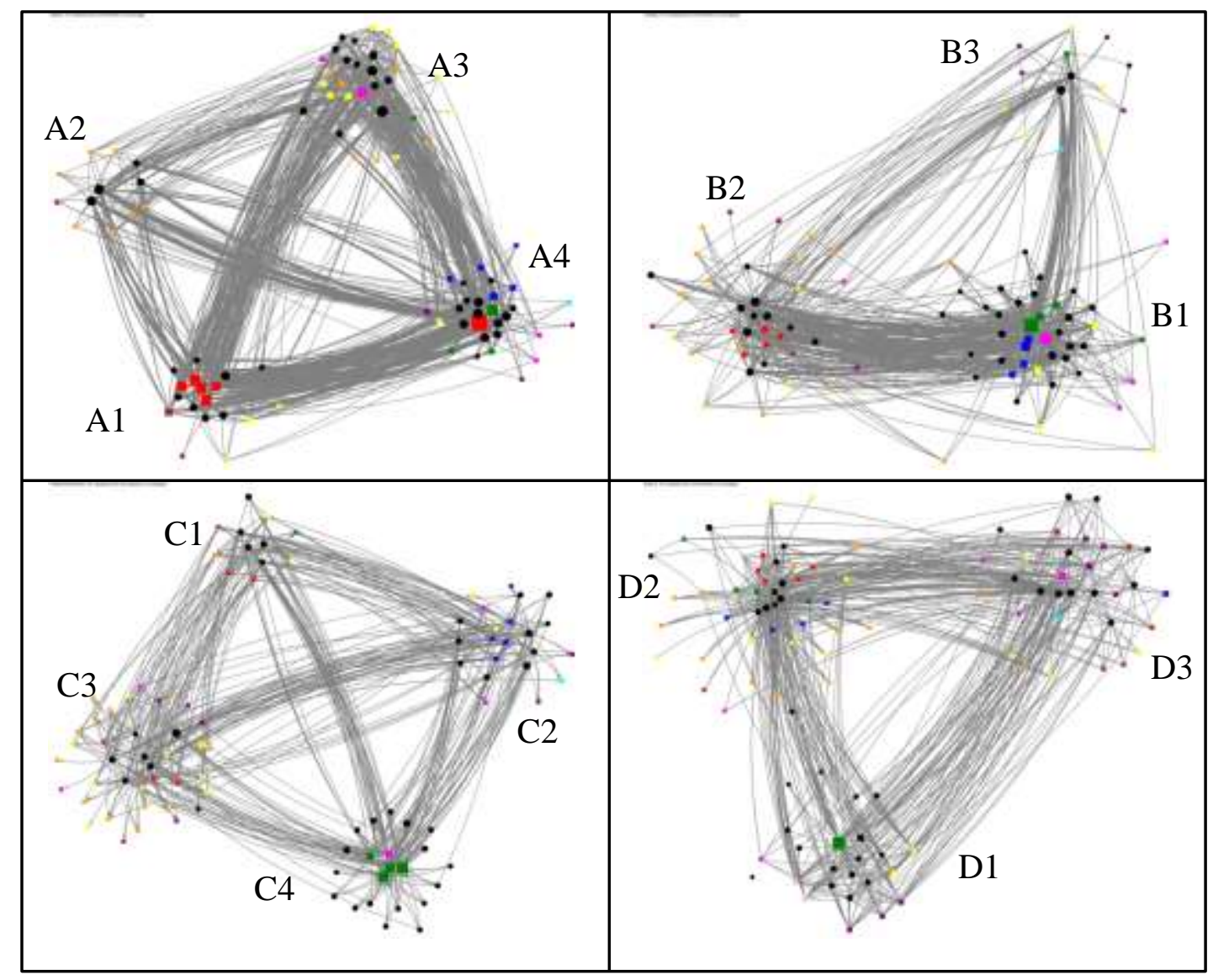

Figure 1: Patterns of resource access during four stages of the module 

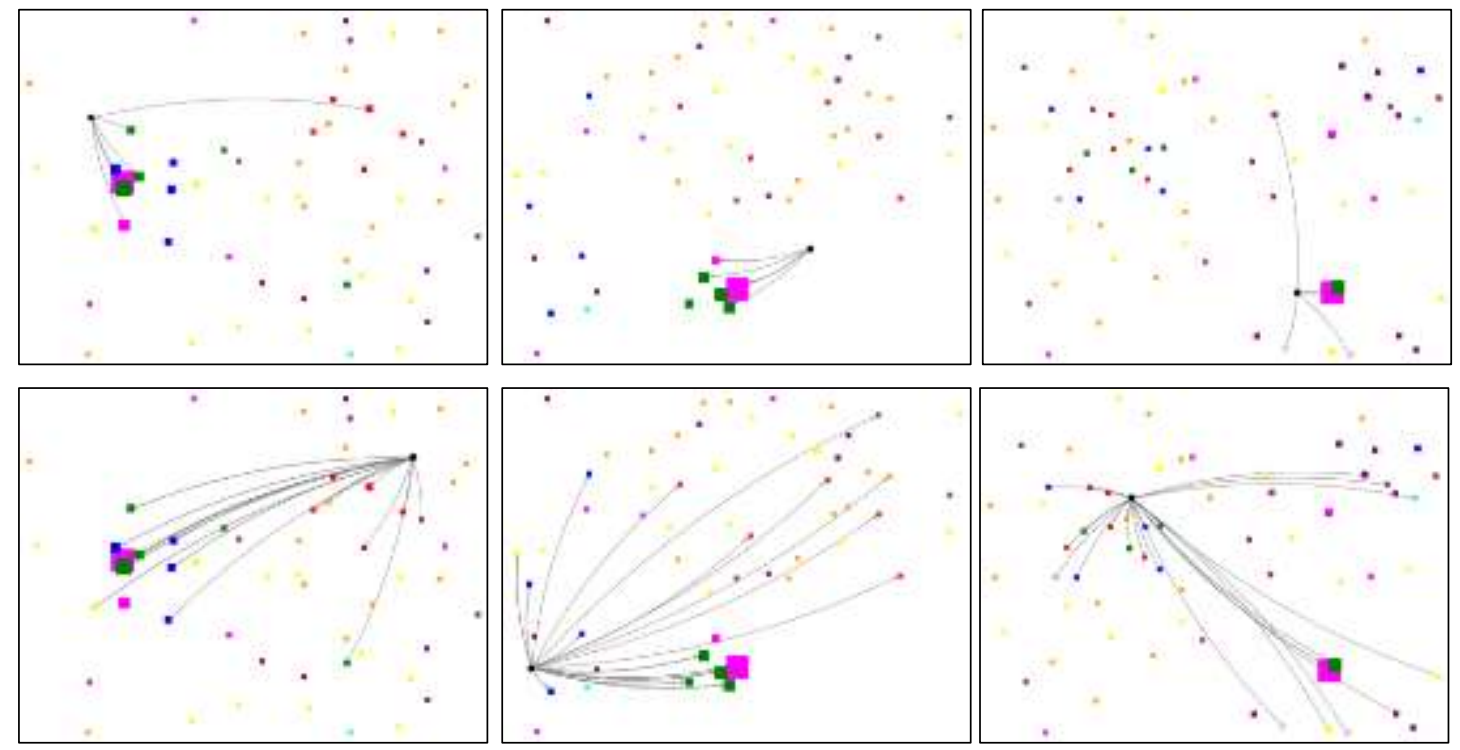

Figure 2: Individual participants' connections with instructor-created resources in three sequential periods of the module 